\title{
COPD in nonsmokers: the biomass hypothesis - to be or not to be?
}

\author{
Louisa Gnatiuc ${ }^{1}$ and Gaetano Caramori²
}

Affiliations: ${ }^{1}$ National Heart and Lung Institute, Dept of Respiratory Epidemiology, Occupational Medicine and Public Health, Imperial College London, London, UK. ${ }^{2}$ Dipartimento di Scienze Mediche, Sezione di Medicina Interna e Cardiorespiratoria, Centro Interdipartimentale per lo Studio delle Malattie Infiammatorie delle Vie Aeree e Patologie Fumo-Correlate (CEMICEF), Università di Ferrara, Ferrara, Italy.

Correspondence: Gaetano Caramori, CEMICEF, Sezione di Medicina Interna e Cardiorespiratoria, Dipartimento di Scienze Mediche Università di Ferrara, Via Savonarola 9, 44121 Ferrara, Italy.

E-mail: gaetano.caramoriđunife.it

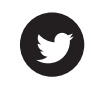

@ERSpublications

Never-smoker COPD remains open to research of the aetiology of lung function impairment http://ow.ly/tYsqc

The Global Burden of Disease study estimated that exposure to particulates resulting from household solid fuel or biomass burning is the third leading risk factor for global disease burden between 1990 and 2010, and that $5 \%$ of the world's disability-adjusted life-years could be attributed to those exposures [1]. Based on population surveys and census data on households using solid fuels for cooking, the report draws public health attention to what is a prevalent, yet preventable or modifiable, health risk for some major lung and heart diseases (respiratory tract and lung cancers, chronic obstructive pulmonary disease (COPD), and cerebrovascular and ischaemic heart disease). The message is of particular interest for developing countries where the exposure is more common and the estimated attributable burden of disease is considerably higher than in developed countries.

In 2010, the American Thoracic Society (ATS) published an official policy statement inviting us to think of COPD differently. Novel risk factors for COPD, in addition to cigarette smoking, were proposed, including exposure to indoor air pollution due to biomass combustion for domestic purposes [2]. The statement was supported by increasing ecological evidence and epidemiological studies suggesting that chronic respiratory disease is more common in populations where the use of biomass is widespread, and that nonsmoking COPD in particular is higher among women cooking with open-fire stoves in unventilated rooms [3].

Two major systematic reviews and meta-analyses combining 15 and 23 adult studies on chronic lung disease epidemiology were subsequently published in 2010. They report an overall 2.3-2.8-fold significantly increased odds for chronic airflow obstruction (CAO) in adults exposed to unclean fuels (coal, charcoal, wood, dung or crop residues) or, in some cases, to clean fuels (liquefied petroleum gas, electricity or gas stoves) $[4,5]$. Similar findings for COPD were reported by a third meta-analysis of studies in rural women [6]. The report by Hu et al. [5] presents, in addition, some dose-response relationship of disease with length of exposures, suggesting possible causality. However, the authors acknowledge some degree of publication bias, particularly for studies where COPD was diagnosed on lung function criteria. While the limitation of predominantly cross-sectional data was stressed, the need for longitudinal cohort studies or studies of personal exposure measurements was recognised for ascertainment of causal links.

In this issue of the European Respiratory Journal, SMITH et al. [7] report recent findings from the China Kadoorie Biobank, a study of $>300000$ nonsmoking Chinese adults living in 10 rural and urban areas. The authors show that the presence of airflow obstruction is common in never-smokers, particularly in rural areas, and it was associated with low socioeconomic status, a history of tuberculosis and low body mass

Received: Feb 122014 | Accepted: Feb 172014

Conflict of interest: None declared.

Copyright @ERS 2014 
index. They also show associations of low lung function with cooking with coal in the current house (OR $1.10,95 \%$ CI 1.04-1.17) or always (OR 1.29, 95\% CI 1.14-1.47), and with heating the house with unknown fuels (OR 2.65, 95\% CI 2.15-3.27), but only in women. The authors acknowledge that the effect attenuation after adjustment for confounding and for region, and any possible effect modification of ventilation in relation to certain fuels, cannot ascertain causality of biomass burning. These largely negative results are perhaps surprising, yet not totally isolated. Two of the other biggest studies to date failed to find any positive association between confirmed airflow obstruction and exposure to biomass in various populations, including China $[8,9]$. This is by far the largest study of this sort to date, bringing valuable information towards understanding the epidemiology of nonsmoking COPD. However, it cannot overcome the limitations of the cross-sectional design, the participant-reported exposure and some possible residual confounding by a lack of information on never having smoked any cigarette.

It is regrettable that the report is based on pre-bronchodilator lung function data, for which acceptability and repeatability could not be fully assessed against the ATS/European Respiratory Society criteria. This is particularly relevant because other common causes of CAO in adult never-smokers (table 1), like bronchial asthma with fixed airflow obstruction, would have been interesting to disentangle [3, 10-16]. In addition, it would have been informative to be able to assess how potential selection bias and relatively low response rates could affect the generalisability of the results.

Given the wealth of the data this study provides, it would have also been very informative to have information on bronchiectasis, which is also another common cause of CAO in adult never-smokers [18], but we recognise that reliable diagnosis would have required chest computed tomography, which, due to the ethical implications related to radiation exposure and given the general population design of the Kadoorie study, would have been beyond the scope of this study.

There is growing evidence supporting a positive association between a history of pulmonary tuberculosis and CAO, independent of cigarette smoking [16]. SMITH et al. [7] found significant, independent associations of CAO with reported history of tuberculosis and also with low household income. Given that pulmonary tuberculosis has a well-defined natural history, distinct from tobacco smoking-related COPD, these associations should be regarded as complications of healed pulmonary tuberculosis and should be considered as a differential diagnosis of COPD in nonsmoking adults, until a better understanding of causal links can be established through cohort studies. Whether poverty and use of biomass are associated with

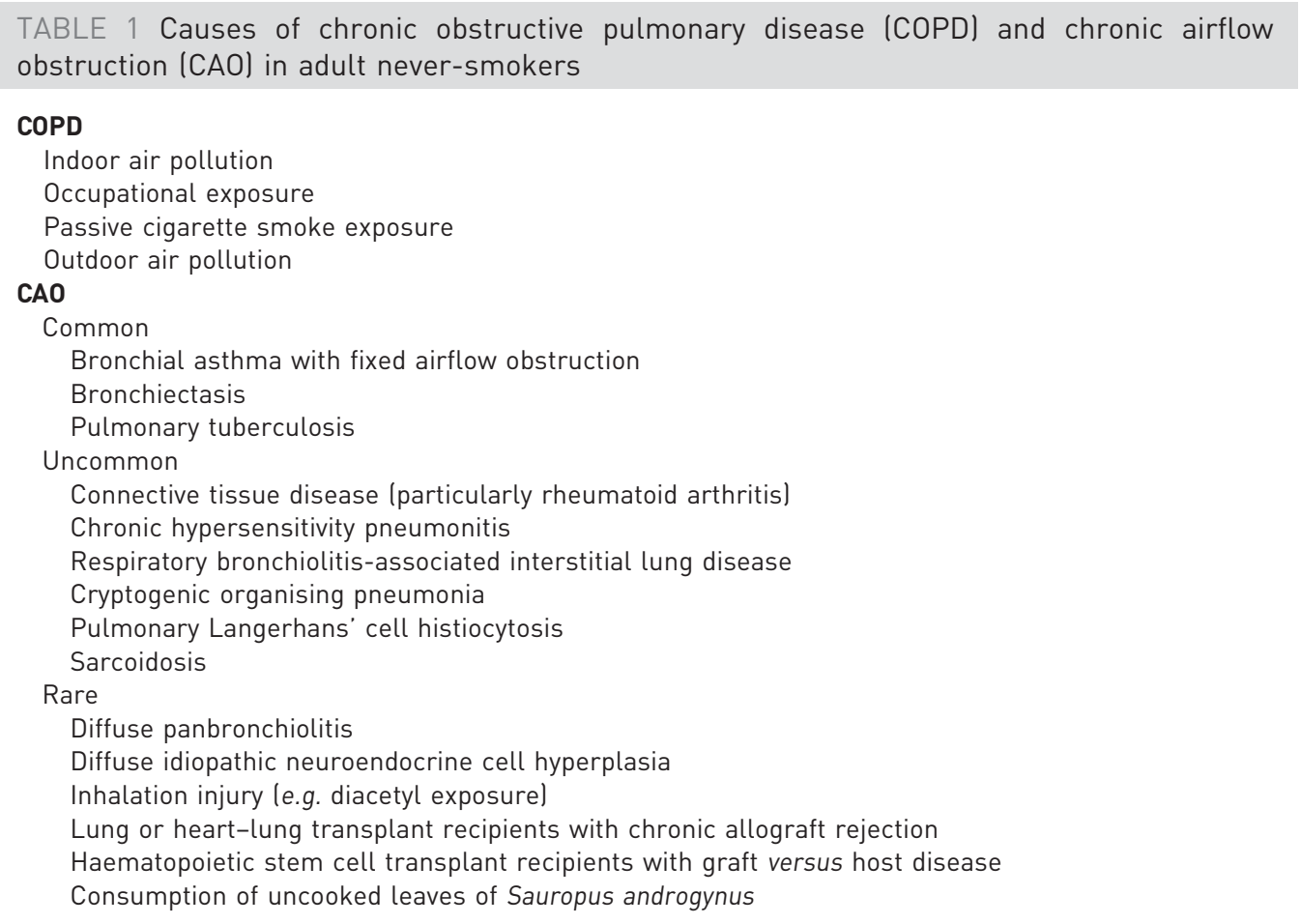

Data from [3, 10-18]. 
each other, or whether poverty contributes to developing COPD in nonsmokers through different avenues, would be an interesting glimpse for public health.

Without doubt, the report by SMITH et al. [7] is a convincing, valuable addition to the current evidence, even if it challenges the traditional view of burning of biomass as an "established" risk factor for chronic respiratory disease, including COPD. These results should be replicated by other (ideally) longitudinal studies and the implications for public health policy to reduce household air pollution should be perhaps revisited in the light of consistent, comparable and convincing evidence. Understanding the natural history of COPD in general and of never-smoker COPD in particular [19] remains an open field for researching the aetiology of lung function impairment and of COPD as a disease, as well as for better understanding clinical phenotypes of this chronic respiratory disease.

\section{References}

1 Lim SS, Vos T, Flaxman AD, et al. A comparative risk assessment of burden of disease and injury attributable to 67 risk factors and risk factor clusters in 21 regions, 1990-2010: a systematic analysis for the Global Burden of Disease Study 2010. Lancet 2012; 380: 2224-2260.

2 Eisner MD, Anthonisen N, Coultas D, et al. An official American Thoracic Society public policy statement: novel risk factors and the global burden of chronic obstructive pulmonary disease. Am J Respir Crit Care Med 2010; 182: 693-718.

3 Salvi SS, Barnes PJ. Chronic obstructive pulmonary disease in non-smokers. Lancet 2009; 374: 733-743.

4 Kurmi OP, Semple S, Simkhada P, et al. COPD and chronic bronchitis risk of indoor air pollution from solid fuel: a systematic review and meta-analysis. Thorax 2010; 65: 221-228.

5 Hu G, Zhou Y, Tian J, et al. Risk of COPD from exposure to biomass smoke: a metaanalysis. Chest 2010; 138: $20-31$.

6 Po JY, Fitzgerald JM, Carlsten C. Respiratory disease associated with solid biomass fuel exposure in rural women and children: systematic review and meta-analysis. Thorax 2011; 66: 232-239.

7 Smith M, Li L, Augustyn M, et al. Prevalence and correlates of airflow obstruction in $~ 317000$ never-smokers in China. Eur Respir J 2014; 44: 66-77.

8 Jindal SK, Aggarwal AN, Chaudhry K, et al. A multicentric study on epidemiology of chronic obstructive pulmonary disease and its relationship with tobacco smoking and environmental tobacco smoke exposure. Indian J Chest Dis Allied Sci 2006; 48: 23-29.

9 Hooper R, Burney P, Vollmer WM, et al. Risk factors for COPD spirometrically defined from the lower limit of normal in the BOLD project. Eur Respir J 2012; 39: 1343-53.

10 Global Initiative for Chronic Obstructive Lung Disease. Global Strategy for the Diagnosis, Management and Prevention of Chronic Obstructive Pulmonary Disease. www.goldcopd.org/uploads/users/files/GOLD_ Report2014_Feb07.pdf Date last accessed: January 21, 2014. Date last updated: 2014.

11 Global Initiative for Asthma. Global strategy for Asthma Management and Prevention. www.ginasthma.org/local/ uploads/files/GINA_Report_March13.pdf Date last accessed: January 21, 2014. Date last updated: 2012.

12 Lynch JP 3rd, Weigt SS, DerHovanessian A, et al. Obliterative (constrictive) bronchiolitis. Semin Respir Crit Care Med 2012; 33: 509-532.

13 Nassar AA, Jaroszewski DE, Helmers RA, et al. Diffuse idiopathic pulmonary neuroendocrine cell hyperplasia: a systematic overview. Am J Respir Crit Care Med 2011; 184: 8-16.

14 Papiris SA, Malagari K, Manali ED, et al. Bronchiolitis: adopting a unifying definition and a comprehensive etiological classification. Expert Rev Respir Med 2013; 7: 289-306.

15 Burgel PR, Bergeron A, de Blic J, et al. Small airway diseases, excluding asthma and COPD: an overview. Eur Respir Rev 2013; 22: 131-147.

16 Allwood BW, Myer L, Bateman ED. A systematic review of the association between pulmonary tuberculosis and the development of chronic airflow obstruction in adults. Respiration 2013; 86: 76-85.

17 Hagstad S, Bjerg A, Ekerljung L, et al. Passive smoking exposure is associated with increased risk of COPD in neversmokers. Chest 2013 [In press DOI: 10.1378/chest.13-1349].

18 Sexton P, Black P, Wu L, et al. Chronic obstructive pulmonary disease in non-smokers: a case-comparison study. COPD 2014; 11: 2-9.

19 Thomsen M, Nordestgaard BG, Vestbo J, et al. Characteristics and outcomes of chronic obstructive pulmonary disease in never smokers in Denmark: a prospective population study. Lancet Respir Med 2013; 1: 543-550. 